\title{
AXL/epidermal growth factor receptor (EGFR) complexes in breast cancer - culprits for resistance to EGFR inhibitors?
}

\author{
Marinus R Heideman and Nancy E Hynes
}

\begin{abstract}
Epidermal growth factor receptor (EGFR) is highly expressed in triple-negative breast cancer (TNBC), and elevated levels correlate with poor prognosis. In analogy with the paradigm of oncogene addiction, blocking EGFR in TNBC was expected to have clinical efficacy - but this has not been the case. Reasons for these results have remained elusive. Recently, Meyer and colleagues showed interplay between EGFR and the epithelial-to-mesenchymal transition-associated AXL receptor in TNBC cells, which might provide some clues.
\end{abstract}

\section{Background}

Many members of the receptor tyrosine kinase (RTK) superfamily are deregulated in cancer [1]. Epidermal growth factor receptor (EGFR) and ErbB2 were the first receptors found mutated and/or overexpressed in human tumors and clinical data suggested that patients with alterations had a poor clinical prognosis [2]. This inspired the major effort that went into developing the plethora of EGFR and ErbB2 inhibitors now available, including antibodies targeting their ectodomains and small molecular weight kinase inhibitors. Blocking EGFR and ErbB2 in specific cancer types has been a major breakthrough in patient treatment [2].

Considering breast cancer, EGFR is robustly expressed in a high proportion of the triple-negative breast cancer (TNBC) subgroup, which comprises only about $15 \%$ of breast cancers but accounts for many deaths due to its aggressive nature [3]. This subtype lacks estrogen and progesterone receptors and the ERBB2 amplicon, and accordingly patients cannot be treated with endocrine or

\footnotetext{
* Correspondence: nancy.hynes@fmi.ch

Department of Mechanisms of Cancer, Friedrich Miescher Institute for Biomedical Research, Maulbeerstrasse 66, 4058, Basel, Switzerland
}

ErbB2 therapies. The poor clinical activity of the EGFR inhibitors in TNBC has thus been very disappointing [4]. Meyer and colleagues have focused on crosstalk between EGFR and the AXL receptor as a possible mechanism to circumvent EGFR inhibition [5].

AXL is an RTK associated with epithelial-to-mesenchymal transition, a process that enhances migratory and invasive potential of tumor cells [6]. AXL levels are high in different types of human cancers, including breast cancer, and this overexpression correlates with poor patient outcome. Moreover, elevated AXL levels have been linked to acquired resistance to EGFR inhibitors in lung cancer $[7,8]$. The work presented by Meyer and colleagues suggests that AXL might be responsible for inherent EGFR inhibitor resistance in TNBC.

\section{The article}

Using a bioinformatics approach, the authors uncovered AXL expression as a predictor of resistance for EGFR inhibitor-based therapies. They subsequently used TNBC models, which highly express AXL and EGFR, to study crosstalk between these receptors. Interestingly, stimulation of the EGFR resulted in ligand-independent transactivation of AXL. Moreover, knockdown of AXL diminished EGFR downstream signaling, indicating a synergistic role for AXL in amplification of EGFR signaling. Cross-linkingmediated immunoprecipitation of AXL revealed binding to EGFR, suggesting that transactivation of AXL occurs via clustering with EGFR at the membrane. In addition, several other RTKs were found to cluster with AXL, implying that AXL might also influence their downstream signaling.

\section{The viewpoint}

Nonsmall-cell lung tumors harboring activating mutations in the EGFR kinase domain respond well to EGFR inhibitors such as erlotinib and gefinitib [9]. However, resistance usually occurs within 12 months and patients become unresponsive. One mechanism observed for this 
acquired resistance is epithelial-to-mesenchymal transition [10], and a seminal paper by Zhang and colleagues revealed that AXL activation is a cause of EGFR inhibitor resistance [7]. In line with these studies, Meyer and colleagues have identified AXL overexpression as a general predictor of resistance to EGFR inhibitors and uncovered a potential mechanism whereby both receptors co-localize and EGFR transactivates AXL, resulting in fine-tuning and diversification of downstream signaling [5]. Crosstalk between RTKs is widespread; for example, ErbB3 robustly couples to the phosphoinositide 3-kinase pathway and it is used by EGFR and ErbB2 as well as other RTKs to activate this pathway [11].

A large proportion of the TNBC subtype overexpresses EGFR, which is associated with poor prognosis. Of note, activating mutations in the EGFR kinase domain have only been sporadically reported in breast cancer $[12,13]$, one reason why TNBC patients might not have responded well to EGFR inhibitor therapies in clinical trials [4]. As an alternative explanation, Meyer and colleagues suggest that AXL, the expression of which is associated with epithelialto-mesenchymal transition, takes over signaling pathways controlled by EGFR. Metastatic lesions have in general reverted to an epithelial signature by so-called mesenchymalto-epithelial transition $[14,15]$. As activating mutations in AXL have not been found in breast cancer, it will be important to determine whether overexpressed activated AXL in the primary tumor predicts AXL activity in the metastatic lesion. To address this, future studies should determine AXL expression in sets of matched primary and metastatic breast tumors.

Mechanistically, the data presented by Meyer and colleagues have other important clinical implications. They showed that EGFR transactivates AXL without a requirement for AXL ligands, suggesting that targeting AXL with blocking antibodies might not be sufficient to inhibit the receptor. As mentioned in their work, additional RTKs also transactivate AXL, suggesting a wider role for AXL in response to targeted RTK inhibitors. Furthermore, development of more specific AXL kinase domain inhibitors would be very important since these are currently lacking. Future clinical studies will reveal the true value of AXL as a target in breast cancer, either as a single target or combined with therapy against EGFR and/or other RTKs.

\section{Abbreviations}

EGFR: Epidermal growth factor receptor; RTK: Receptor tyrosine kinase; TNBC: Triple-negative breast cancer.

\section{References}

1. Lemmon MA, Schlessinger J: Cell signaling by receptor tyrosine kinases. Cell 2010, 141:1117-1134.

2. Yarden $Y$, Pines G: The ERBB network: at last, cancer therapy meets systems biology. Nat Rev Cancer 2012, 12:553-563.

3. Carey L, Winer E, Viale G, Cameron D, Gianni L: Triple-negative breast cancer: disease entity or title of convenience? Nat Rev Clin Oncol 2010, 7:683-692.

4. Crown J, O'Shaughnessy J, Gullo G: Emerging targeted therapies in triplenegative breast cancer. Ann Oncol 2012, 23(Suppl 6):vi56-vi65.

5. Meyer AS, Miller MA, Gertler FB, Lauffenburger DA: The receptor AXL diversifies EGFR signaling and limits the response to EGFR-targeted inhibitors in triple-negative breast cancer cells. Sci Signal 2013, 6:ra66.

6. Vuoriluoto K, Haugen H, Kiviluoto S, Mpindi JP, Nevo J, Gjerdrum C, Tiron C, Lorens JB, Ivaska J: Vimentin regulates EMT induction by Slug and oncogenic $\mathrm{H}$-Ras and migration by governing $\mathrm{Axl}$ expression in breast cancer. Oncogene 2011, 30:1436-1448.

7. Zhang Z, Lee JC, Lin L, Olivas V, Au V, LaFramboise T, Abdel-Rahman M, Wang X, Levine AD, Rho JK, Choi YJ, Choi CM, Kim SW, Jang SJ, Park YS, Kim WS, Lee DH, Lee JS, Miller VA, Arcila M, Ladanyi M, Moonsamy P, Sawyers C, Boggon TJ, Ma PC, Costa C, Taron M, Rosell R, Halmos B, Bivona TG: Activation of the AXL kinase causes resistance to EGFR-targeted therapy in lung cancer. Nat Genet 2012, 44:852-860.

8. Byers LA, Diao L, Wang J, Saintigny P, Girard L, Peyton M, Shen L, Fan Y, Giri U, Tumula PK, Nilsson MB, Gudikote J, Tran H, Cardnell RJ, Bearss DJ, Warner SL, Foulks JM, Kanner SB, Gandhi V, Krett N, Rosen ST, Kim ES, Herbst RS, Blumenschein GR, Lee JJ, Lippman SM, Ang KK, Mills GB, Hong WK, Weinstein JN, Wistuba II, Coombes KR, Minna JD, Heymach JV: An epithelial-mesenchymal transition gene signature predicts resistance to EGFR and PI3K inhibitors and identifies AxI as a therapeutic target for overcoming EGFR inhibitor resistance. Clin Cancer Res 2013, 19:279-290.

9. Sharma SV, Bell DW, Settleman J, Haber DA: Epidermal growth factor receptor mutations in lung cancer. Nat Rev Cancer 2007, 7:169-181.

10. Sequist LV, Waltman BA, Dias-Santagata D, Digumarthy $S$, Turke AB, Fidias $P$, Bergethon K, Shaw AT, Gettinger S, Cosper AK, Akhavanfard S, Heist RS, Temel J, Christensen JG, Wain JC, Lynch TJ, Vernovsky K, Mark EJ, Lanuti M, lafrate AJ, Mino-Kenudson M, Engelman JA: Genotypic and histological evolution of lung cancers acquiring resistance to EGFR inhibitors. Sci Transl Med 2011, 3:75ra26.

11. Hynes NE, Ingham PW, Lim WA, Marshall CJ, Massague J, Pawson T: Signalling change: signal transduction through the decades. Nat Rev Mol Cell Biol 2013, 14:393-398.

12. Teng YH, Tan WJ, Thike AA, Cheok PY, Tse GM, Wong NS, Yip GW, Bay BH, Tan PH: Mutations in the epidermal growth factor receptor (EGFR) gene in triple negative breast cancer: possible implications for targeted therapy. Breast Cancer Res 2011, 13:R35.

13. Reis-Filho JS, Pinheiro C, Lambros MB, Milanezi F, Carvalho S, Savage K, Simpson PT, Jones C, Swift S, Mackay A, Reis RM, Hornick JL, Pereira EM, Baltazar F, Fletcher CD, Ashworth A, Lakhani SR, Schmitt FC: EGFR amplification and lack of activating mutations in metaplastic breast carcinomas. J Pathol 2006, 209:445-453.

14. Tarin D, Thompson EW, Newgreen DF: The fallacy of epithelial mesenchymal transition in neoplasia. Cancer Res 2005, 65:5996-6000. discussion 6000-6001.

15. Gunasinghe NP, Wells A, Thompson EW, Hugo HJ: Mesenchymal-epithelial transition (MET) as a mechanism for metastatic colonisation in breast cancer. Cancer Metastasis Rev 2012, 31:469-478.

$10.1186 / \mathrm{bcr} 3564$

Cite this article as: Heideman and Hynes: AXL/epidermal growth factor receptor (EGFR) complexes in breast cancer - culprits for resistance to EGFR inhibitors? Breast Cancer Research 2013, 15:315 